\title{
Hemofilias: Fisiopatologia, Diagnóstico e Tratamento
}

Hemophilia: Pathophysiology, Diagnosis and Treatment

Roberta Truzzi COLOMBO, Gerson ZANUSSO JÚNIOR

Faculdade Ingá - Uningá: Rodovia PR 317, 6114, CEP 87035-510, Maringá, Brasil. E-mail: gersonjr17@hotmail.com

\begin{abstract}
Hemophilia is a serious hereditary blood coagulation disorder caused by a deficiency of clotting activity of factor VIII (hemophilia A) or IX (hemophilia B). The disease is caused by alterations in the coding genes of these factors located on the long arm of the sex chromosome X. Thus its occurrence in males is almost exclusive due to the man's presenting only one $\mathrm{X}$ chromosome. The severity of the disease can vary from severe, mild and moderately severe after dosage of the factors VIII and IX clotting. One of the most feared complications of patients with this disease refers to the development of inhibitors that are antibodies directed against the factors infused. The diagnosis is made through laboratory tests, mainly by coagulation profile and serum specific factors, based on the clinical manifestations of the patient. Hemophilia is not curable, and the basis of its treatment is the infusion of the deficient factor concentrate. However, patients may develop specific inhibitors to the factors infused and in these cases the treatment alternatives are the use of biotechnology to new drugs and the use of gene therapy.
\end{abstract}

Keywords: Hemophilia, diagnosis, coagulation factors; treatment.

\section{RESUMO}

A hemofilia é um grave distúrbio hereditário da coagulação sanguínea, causada pela deficiência da atividade coagulante do fator VIII (hemofilia A) ou IX (hemofilia B). A doença é decorrente de alterações nos genes codificantes destes fatores localizados no braço longo do cromossomo sexual X. Assim sua ocorrência no sexo masculino é quase que exclusiva, devido o homem apresentar somente um cromossomo X. A gravidade da doença pode variar em severa, moderadamente severa e leve, após dosagem dos fatores VIII e IX da coagulação. Uma das complicações mais temíveis dos pacientes com esta doença refere-se ao desenvolvimento de inibidores, que são anticorpos direcionados contra os fatores infundidos. O diagnóstico da doença é realizado através de exames laboratoriais, principalmente pelo coagulograma completo e dosagem de fatores específicos, baseando-se nas manifestações clínicas apresentadas pelo paciente. A hemofilia não tem cura e a base do seu tratamento é a infusão do concentrado do fator deficiente. No entanto, pacientes podem desenvolver inibidores específicos para os fatores infundidos e, nestes casos as alternativas de tratamento são o uso da biotecnologia para novos medicamentos e o uso da terapia gênica.

Palavras Chave: Hemofilia; diagnóstico; fatores de coagulação; tratamento. 


\section{INTRODUÇÃO}

A hemofilia, uma coagulopatia hereditária, caracteriza-se pela deficiência da atividade coagulante do fator VIII (hemofilia A) ou IX (hemofilia B). Esta doença é decorrente de alterações nos genes codificantes destes fatores. Assim, sua ocorrência no sexo masculino é quase exclusiva, devido ao fato de o homem apresentar somente um cromossomo X. Porém, as mulheres atuam como portadoras, quando apresentam um dos cromossomos X marcado com o gene hemofílico (1).

A hemofilia $\mathrm{A}$, conhecida como Clássica, atinge cerca de $85 \%$ dos pacientes, enquanto a hemofilia B, conhecida como Fator Christmas, atinge cerca de $15 \%$ dos pacientes (2).

A prevalência das hemofilias nos diversos grupos étnicos é de aproximadamente 1:10.000 e 1:40.000 a 50.000 nascimentos masculinos $(3,4)$. Assim, a cada 10 mil indivíduos do sexo masculino nascidos 1-2 são afetados com a doença (5). No Brasil, em 2007, foi traçado um panorama da distribuição de todas as coagulopatias hereditárias, pela Coordenação de Política Nacional de Sangue e Hemoderivados (CPNS), com base em informações encaminhadas pelos Estados. O estudo apontou a existência de 8.168 pacientes cadastrados, dos quais 6.885 portadores de hemofilia A e 1.283 portadores de hemofilia B (6).

As hemofilias podem decorrer de fatores hereditários ou adquiridos. As formas adquiridas são mais raras, podendo resultar do desenvolvimento de alo-anticorpos, associados a doenças autoimunes, câncer ou causas de origem idiopática (4). A hemofilia A adquirida é uma alteração rara da coagulação sanguínea, que consiste no aparecimento de anticorpos circulantes contra a atividade pró-coagulante do fator VIII. Essa condição pode ser relatada em associação com doenças como artrite reumatoide, lúpus eritematoso sistêmico e Síndrome de Sjögren. Este tipo de hemofilia tem sido relatada em idosos sadios, mulheres no pós-parto, além de ser relacionada ao uso de fármacos como a penicilina (7).

Tanto a hemofilia A, como a hemofilia B apresentam as mesmas características genéticas e clínicas, apresentando as mesmas anormalidades em testes de triagem (8). Para diferenciá-las é necessário fazer a dosagem das atividades dos anticoagulantes dos fatores VIII e IX em ensaios específicos. Isso se faz necessário porque o sangramento com frequência é tratado com concentrados de plasma contendo um dos fatores, mas não ambos (9).

A classificação clínica das hemofilias baseia-se nos níveis plasmáticos de antígeno (Ag) ou atividade coagulante do fator deficiente. Podem ocorrer hemorragias sob a forma de hematúria, epistaxe, melena/hematêmese, ou se apresentarem como hematomas, sangramentos retro- peritoniais e intra-articulares (hemartroses), que constituem um dos aspectos mais característicos das formas graves da doença (3).

Em indivíduos que apresentam hemofilia A grave (aproximadamente 50\% dos casos), um processo hemorrágico pode ocorrer espontaneamente, enquanto que em pacientes com hemofilia moderada (cerca de 10\% dos casos) apresentam um fenótipo intermediário. Pacientes portadores da forma leve da doença (30 a 40\% dos casos) sofrem hemorragias pós-trauma ou pós-cirurgia (5).

Sendo a hemofilia uma doença que atinge um número considerável de pacientes, este trabalho teve por objetivo realizar uma revisão bibliográfica sobre a fisiopatologia, classificação, formas de diagnóstico, tratamento convencional e avanços da biotecnologia.

\section{Histórico da doença}

O caso mais antigo da doença é relatado no Talmude (10). Neste são encontrados dois relatos de famílias que perderam seus dois primeiros filhos após o acontecimento de uma intensa hemorragia. Devido o desconhecimento real da causa, os rabinos sugeriam que este fato acontecia somente com mulheres que se casavam duas vezes (11).

O relato mais conhecido da história da hemofilia é o da Família Real inglesa, que com o passar dos séculos, espalhou-se pela Europa em consequência de vários casamentos realizados pelos descendentes da Rainha Vitória (12).

\section{Fisiologia da coagulação}

Quando a parede de um vaso sanguíneo é lesada, inicia-se um processo denominado hemostasia, que tem por função impedir a perda de sangue (13). A hemostasia é provocada por meio de diversos mecanismos: (a) constrição vascular, (b) formação de tampão de plaquetas, (c) formação de coágulo sanguíneo, como resultado da coagulação do sangue, e (d) eventual crescimento de tecido fibroso no coágulo, para o fechamento permanente do orifício do vaso (14).

A primeira etapa do processo de hemostasia consiste na constrição imediata dos vasos danificados, diminuindo temporariamente o fluxo e a pressão dentro do vaso, auxiliando na formação do tampão plaquetário. Em seguida, as plaquetas ligam-se ao colágeno exposto e tornam-se ativas liberando citocinas dentro da área e torno da lesão. Simultaneamente, o colágeno exposto e fatores presentes nos tecidos iniciam uma série de reações conhecidas como cascata da coagulação. Nesta cascata, proteínas inativas do plasma são convertidas em enzimas ativas. A enzima trombina converte o fibrinogênio em fibrina reforçando o tampão plaquetário que passa a ser conhecido como coágulo (15). 
No processo de coagulação do sangue, participam várias substâncias denominadas fatores da coagulação. Muitos são pró-enzimas sintetizadas pelo fígado e que se transformam em enzimas durante o processo de coagulação (16). A coagulação é dividida em duas vias: uma via intrínseca, que inclui os seguintes fatores: XII, XI, IX, VIII, precalicreína, e cininogênio de alto peso molecular, e uma via extrínseca, que inclui o fator VII. Estas duas vias unem-se em uma via comum, que compreende os seguintes fatores: V, X, II e I, cuja função é criar a trombina, que converte o fibrinogênio em fibrina formando um coágulo estável (15).

O sistema intrínseco compreende os fatores da coagulação presentes no plasma associados ao cálcio e plaquetas. Possivelmente, o contato com uma superfície estranha diferente do endotélio vascular remove do sangue u inibidor da coagulação. Assim, o fator XII atua enzimaticamente, ativando progressivamente os fatores XI, IX, VII, V e X da coagulação. O sistema extrínseco tem função de ativar o fator VII, e este atua enzimaticamente sobre os fatores $\mathrm{V}$ e X. A hemostasia depende, portanto, da integridade de cada um dos fatores da coagulação (16).

\section{Fisiopatologia da coagulação}

A coagulação do sangue compreende uma série de reações bioquímicas sequenciais envolvendo a interação de proteínas, comumente referidas como fatores da coagulação, além de células, particularmente as plaquetas e íons. Este processo leva à formação de um coágulo, cujo principal componente é a fibrina. $\mathrm{Na}$ deficiência de um destes fatores da coagulação pode ocasionar doenças hemorrágicas, ou coagulopatias. As principais manifestações clínicas destas doenças são os sangramentos espontâneos ou após um trauma ou cirurgia (4). As hemofilias A e B, juntamente com a doença de von Willebrand, são as coagulopatias hereditárias de maior prevalência na população mundial e resultam em sangramentos prolongados. As hemofilias A e B caracterizam-se pela redução da atividade dos fatores da coagulação VIII e IX, respectivamente. A hemofilia A é responsável por $75 \%$ a $80 \%$ dos casos, e a hemofilia B, por $20 \%$ a $25 \%$.

\section{Manifestações genéticas}

A hemofilia é uma doença hemorrágica genético-hereditária de caráter recessivo condicionada por um gene localizado no braço longo do cromossomo sexual X $(6,17)$. A hemofilia $\mathrm{A}$ está ligada à presença de um gene anormal localizada na posição Xq28, no cromossomo X (18). As mutações no enorme gene do fator VIII na ponta do braço longo do cromossomo $\mathrm{X}$, incluem inversões gênicas, deleções, mutações de ponto e inserções (19). O gene que controla a produção do fator IX também se localiza no cromossomo X, mas na posição Xq27 (20).
As características recessivas ligadas ao $\mathrm{X}$ têm um padrão distinto de herança. Primeiro, estas características aparecem mais frequentemente nos homens, pois estes devem herdar apenas uma única cópia do alelo para apresentar a característica, enquanto as mulheres devem herdar duas cópias do alelo, uma de cada genitor, para serem afetadas (21). Uma mutação recessiva ligada ao $\mathrm{X}$ é expressa fenotipicamente em todos os homens que a recebem, mas apenas nas mulheres que são homozigóticas para a mutação (22).

Quando um homem hemofílico se casa com uma mulher normal, seus filhos serão sempre normais, pois o cromossomo Y não transmite a doença. Porém, suas filhas serão todas portadoras. A doença nem sempre se manifesta na geração imediatamente seguinte à de um paciente hemofílico, podendo pular até algumas gerações. A mutação sofrida pelo gene responsável pela síntese do fator VIII ou IX costuma ocorrer em muitas gerações anteriores à do paciente (23). As mulheres, chamadas de portadoras da doença, têm a mesma chance de gerar meninos hemofílicos ou não, ou meninas portadoras ou não (8).

\section{Manifestações clínicas}

A gravidade das manifestações hemorrágicas nas hemofilias varia de acordo com o grau de deficiência do fator. São encontrados três graus de severidade da doença: grave, moderado e leve (24). Os portadores de hemofilia severa possuem atividade coagulante de fator VIII ou IX abaixo de $1 \%$ do normal, os portadores de hemofilia moderadamente severa possuem atividade entre 1 a $5 \%$ do normal e os portadores de hemofilia leve possuem atividade entre 5 e $30 \%$ do normal. Estes dados refletem a existência de diferentes alelos anormais, capazes de manter níveis diferentes de atividade de fator VIII ou IX (9).

As hemorragias ocorrem principalmente sob a forma de hematomas e hemartroses. As hemartroses de repetição quando não tratadas estão associadas à degeneração articular, chamadas de artropatia hemofílica, tendo como conseqüência dor, deformidades articulares e impotência funcional grave (3).

Podem ocorrer hemorragias sob forma de hematúria, epistaxe, melena/hematêmese, ou se apresentarem como hematomas, sangramentos retroperitoniais e intra-articulares (hemartroses), que constituem um dos aspectos mais característicos das formas graves da doença. Nos casos de hematúria o sangramento pode prolongar-se por semanas, mas a avaliação da perda sanguínea somente pelo aspecto da urina é precária, devido a diluição do sangue. Geralmente, as hemorragias desencadeadas por trauma iniciam-se entre uma a três horas após o trauma e podem durar vários dias e, dificilmente, cedem 
à pressão local, diferentemente das hemorragias resultantes de defeito vascular, que são imediatas, cedem em poucas horas e respondem a tratamento local (25).

A hemartrose consiste no extravasamento de sangue para o interior da articulação ou para a cavidade sinovial. É o elemento clínico mais caraterístico da hemofilia e inicia-se geralmente em articulações que suportam o peso na fase em que a criança está aprendendo a andar $(24,26)$. As áreas mais afetadas pelas hemartroses são as articulações do joelho, tornozelo, cotovelo, ombro e coxo-femoral. Devido o sangue permanecer fluido dentro das articulações, há possibilidade de formação de cistos hemorrágicos e danificação da membrana sinovial (3).

Portadores de hemofilia, quando sujeitos a pequenos golpes, movimentos bruscos ou até contrações musculares violentas podem provocar hemorragias subcutâneas, musculares ou intramusculares. Após detecção da hemorragia, a mesma deve ser tratada o mais rápido possível, pois um tratamento tardio pode provocar complicações à saúde. As hemorragias mais freqüentes são no sistema nervoso, nas cavidades oral e nasal, no pescoço e urina (27).

\section{Diagnóstico clínico}

Clinicamente, as hemofilias A e B são literalmente semelhantes, o histórico familiar é importante e, a intensidade dos sintomas variam de acordo com o grau de severidade da doença, conforme a classificação estabelecida pela International Society of Thrombosis and Haemostasis.

Pacientes com a forma leve da doença sangram somente após grandes traumas ou cirurgias; aqueles com hemofilia moderada sangram após traumas médios ou cirurgias e os portadores de hemofilia severa podem sangrar espontaneamente (3). Muitos destes pacientes são atualmente infectados pelo HIV devido à transmissão por infusão do concentrado deficiente no passado. A trombocitopenia imune associada à infecção pelo HIV pode agravar a tendência a sangramentos (28).

\section{Diagnóstico laboratorial}

O diagnóstico laboratorial da hemofilia baseia-se no resultado de TTPA (tempo de tromboplastina parcial ativada) prolongado e deficiência de um dos fatores de coagulação (29). O TTPA valia as vias intrínseca e comum da cascata da coagulação (pré-calicreína, cininogênio de alto peso molecular, fatores XII, XI, IX, VIII, X, $\mathrm{V}$, protrombina e fibrinogênio). O TTPA mostra-se mais sensível a deficiências dos fatores VIII e IX ou fatores da via comum (18).

O coagulograma é um conjunto de exames que deve ser solicitado pelo médico ou dentista para verificar se a coagulação do paciente está normal, sendo fundamental em pré-operatórios (30).

Em testes de triagem, encontra-se em normalidade no tempo de sangramento (TS), pois as rolhas hemostáticas podem formar-se normalmente; tempo de protrombina (TP), porque a elevada concentração de fator tecidual usada neste teste resulta em ativação direta do fator tecidual-fator VII do fator X, que reprimi a necessidade dos fatores VIII e IX; tempo de trombina (TT), devido á reação trombina-fibrinogênio ser normal $(9,31)$.

Os testes laboratoriais com resultados anormais são: tempo de coagulação (TC) aumentado, tempo de tromboplastina parcial ativado (TTPA) aumentado, teste de geração da tromboplastina alterado, consumo de protrombina alterado com protrombina residual do soro aumentado, dosagem dos fatores VIII ou IX alterada com taxas variáveis (23).

Quando o fator IX é o fator deficiente, não são necessários testes posteriores. Mas, se o fator deficiente for o VIII, deve-se dosar o nível plasmático do antígeno Von Willebrand por eletroimunoensaio, para se excluir qualquer possibilidade de doença de Von Willebrand (9).

\section{Dagnóstico diferencial}

Clinicamente, as hemofilias A e B são indistinguíveis e apenas estudos laboratoriais podem mostrar as diferenças entre estas duas patologias (28). O diagnóstico diferencial entre as hemofilias é realizado por meio da dosagem da atividade dos fatores VIII e IX da coagulação (3).

\section{Tratamento e acompanhamento do paciente hemofílico}

A opção terapêutica recomendada atualmente no Brasil para reposição do fator VIII ou IX é o concentrado de fator derivado de plasma humano. Essa escolha leva em consideração aspectos econômicos e segurança na preparação do produto. O Ministério da Saúde é o responsável pela compra e distribuição destes hemoderivados aos centros cadastrados para o tratamento das coagulopatias hereditárias, como a hemofilia (32).

Atualmente, o tratamento administrado a doentes de hemofilia é por meio de concentrados de derivados do plasma humano ou produtos fabricados por engenharia genética (recombinantes). Estes produtos permitem ao doente manter uma vida ativa muito próxima do normal (2).

A terapia farmacológica consiste na administração de Crio-precipitado, Plasma fresco congelado, Concentrado do fator VIII ou IX, Desmopressina, Terapia Antifibrinolitica, Concentrado de fator VIII Porcino e Complexo concentrado de protrombina (29). 
O crio-precipitado é obtido pela centrifugação e congelamento do plasma de um único doador, contendo em cada bolsa aproximadamente 80 Ul de Fator VIII (3). O crio-precipitado não é uma opção terapêutica para portadores de hemofilia $\mathrm{B}$, uma vez que não contém o fator IX (33). Foi utilizado até a década de 80, quando houve o surgimento do problema da contaminação pelo vírus do HIV, detectado no sangue de hemofílicos que receberam crio-precipitado plasmático (34).

O plasma fresco congelado é utilizado desde a década de 50 no tratamento da hemofilia. Sua apresentação é de 175 a $250 \mathrm{~mL}$ por bolsa com 70 a $90 \mathrm{U} / \mathrm{dL}$ de fator VIII, IX e outros fatores coagulantes. Repõe de 15 a $20 \%$ do fator VIII com 800 a $1000 \mathrm{~mL}$ de volume. Pode ser usado para tratar deficiências conhecidas de fatores de coagulação nos casos em que o concentrado específico não esteja disponível (29). O tratamento baseado na infusão de fator VIII pode ser por uso de plasma fresco humano purificado ou obtido por DNA recombinante (35). Porém, existe uma dificuldade na manutenção de níveis adequados dos fatores no plasma, para proteger contra hemorragias, pois sua meia-vida é baixa (10-12h) e é necessária a administração em curtos períodos (2-3 dias) (36).

Além da terapêutica de reposição, a desmopressina, um análogo sintético da vasopressina, é utilizada em casos de hemofilia A leve, mas não na hemofilia B. Nos hemofílicos A que sangram abundantemente a terapia de escolha deve ser o concentrado de fator VIII. O modo de ação dessa droga não está completamente esclarecido, parece que ela aumenta a liberação do fator VIII e fator de Von Willebrand (FvW) dos depósitos $(23,32)$.

Os concentrados liofilizados de fator VIII comerciais são preparados em lotes feitos do "pool" de plasma de 2000-5000 doadores. O pó liofilizado é colocado em frascos de vidro e fornecem 250 a 1000 unidades de fator VIII. O concentrado de fator IX existe sob a forma de um "complexo de protrombina concentrado" liofilizado que contém não apenas fator IX, mas todos os fatores de coagulação dependentes de vitamina K (9).

A combinação da terapia sistêmica de reposição de fatores de coagulação e os agentes anti-fibrinolíticos pode reduzir significativamente os episódios de sangramento. A prescrição do anti-fibrinolítico deve ser realizada pelo médico hematologista, pois em alguns casos, como sangramento do trato urinário, não são indicados (37).

O concentrado de fator VIII porcino é usado em pacientes que possuem inibidores do fator VIII. Após o tratamento, pode ser que o paciente desenvolva inibidores ao fator VIII porcino (29).

O concentrado de complexo protrombínico (CCP) é obtido por fracionamento de "pool" de plasma é utili- zado no tratamento de hemofílicos B que não apresentem riscos de trombose, ou seja, aqueles que não apresentem insuficiência hepática, trauma, trombofilias, coagulopatia de consumo, quando são necessárias poucas infusões ou quando não se dispõe de concentrado de fator IX, e ainda em hemofílicos A que desenvolveram anticorpos específicos contra o fator VIII (25).

Com frequência, os hemofílicos devem receber medicação para combater fenômenos dolorosos. As preparações contendo ácido acetilsalicílico devem ser evitadas, pois inibem a agregação plaquetária e facilitam as hemorragias (23).

No acompanhamento dos pacientes com coagulopatias é fundamental o tratamento das hemorragias agudas, cuidados peri-operatórios e profilaxia das hemorragias. A educação direcionada destes pacientes é importante para a redução da morbidade e mortalidade (38). Vrabic et al (2012), ressaltaram sobre a importância do apoio da família para garantir a continuidade do tratamento preconizado e os aspectos preventivos essenciais (39).

Ainda, Andery et al (2005), defenderam a prática física no auxílio ao tratamento da doença, evitando apenas atividades de contato intenso pois atividade física proporciona melhora no equilíbrio da musculatura, estabilização da articulação, prevenindo possíveis sangramentos, além de contribuir com melhor convívio social (40). Outro benefício relatado é o possível aumento do nível de fator VIII circulante no sangue.

\section{Terapia Gênica}

Com o advento da tecnologia do DNA recombinante, foi viabilizada a clonagem do gene dos fatores de crescimento, o que tornou possível a caracterização molecular do mesmo e o desenvolvimento de proteínas recombinantes (fator VIII e IX recombinante) como uma alternativa terapêutica (41).

A terapia gênica tem como objetivo inserir um novo código normal, nas células que deixaram de produzir corretamente a proteína (fator) devido à mutação presente. Após esta implantação a célula que recebeu este novo gene, passa a ser capaz de produzir o fator continuamente. Como os genes dos fatores VIII e IX já foram decifrados, produziu-se em laboratório através da técnica conhecida como recombinante ou engenharia genética, genes normais para a produção destes fatores (42).

$\mathrm{Na}$ hemofilia, a terapia gênica permite que as células com os genes do fator deficiente sejam induzidas a produzi-los. Para que isso ocorra são necessários o vetor de transporte dos genes, o gene a transferir e a célulaalvo específica. Esta última deve sobreviver um longo período de tempo e ter fácil acesso a circulação sanguí- 
nea. O epitélio intestinal é um alvo atrativo para a terapia gênica da hemofilia, por conta de sua divisão celular acelerada (18).

Para que seja obtido benefício terapêutico é necessário que o gene seja expresso nas células de um tecido do indivíduo que possibilite a liberação do fator de coagulação no sangue. As células do fígado mostraram-se apropriadas, devido este órgão ser intensamente irrigado (43).

\section{Desenvolvimento de inibidores}

Uma das complicações mais temíveis do tratamento dos pacientes com hemofilia refere-se ao desenvolvimento de inibidores, que são anticorpos policlonais da classe da IgG direcionados contra os fatores VIII ou IX infundidos (aloanticorpos) (44). Neste caso, os pacientes acometidos passam a não responder a infusão do fator deficiente e apresentam episódios hemorrágicos de difícil controle. O único tratamento capaz de erradicar inibidores em pacientes com hemofilia congênita é a imunotolerância (25).

O desenvolvimento de uma resposta imune humoral contra o Fator VIII ocorre em aproximadamente $25 \%$ dos indivíduos com hemofilia A grave, 5 a $15 \%$ dos pacientes com hemofilia A leve ou moderada que são tratados com concentrados do Fator VIII purificados do plasma ou Fator VIII recombinante (5) e estudos indicam que o desenvolvimento de inibidores contra o fator VIII é uma resposta imune multifatorial complexa, na qual estão envolvidos fatores genéticos e adquiridos (31). Para os hemofílicos B graves, o desenvolvimento de um inibidor é mais raro e afeta de 1 a $4 \%$ dos doentes. Em hemofílicos com porcentagem do fator VIII superior a 5\% o desenvolvimento de um inibidor é raro (2). Ainda, segundo alguns estudos já realizados, existe correlação entre o desenvolvimento de Inibidores Anti-fator VIII e o genótipo do paciente, além do tipo de mutação gênica (31).

Pacientes com inibidor, em casos de hemorragia aguda, necessitam de terapias alternativas como, altas doses de FVIII humano e remoção do anticorpo por imuno-adsorção ou plasmaferese, seguido de infusão de FVIII (45). Outra possibilidade é o tratamento com produtos de desvio ("by-pass") sendo que, dois desses tratamentos, uso de concentrado do complexo de protrombina ativado (aPCC) e Fator Recombinante VIIa (rFVIIa) vêm sendo utilizados, inclusive no Brasil, mas há discussão sobre o custo-benefício de cada um $(46,47)$. Como a terapia de reposição não é viável na maioria dos tais pacientes, o uso de aPCC e fator VIIa recombinante são imprescindíveis; no entanto, os mesmos têm sido usados com pouca frequência como agentes profiláticos (48).
Livnat et al (2013), confirmaram em estudo a vantagem da combinação in vitro de FVIII e rFVIIa para melhorar a hemostase de forma segura a pacientes com desenvolvimento de inibidores (49). Atualmente, pesquisas são realizadas para melhorar os aspectos farmacocinéticos dos fatores utilizados na terapêutica. Proteínas de fusão recombinantes que ligam fatores de coagulação VII e IX com albumina (rVIIa-FP e Rix-FP, respectivamente) têm uma meia-vida mais longa. Outro avanço na terapia foi a descoberta do fator VIII de cadeia única recombinante, o qual melhorou a estabilidade intrínseca e uma maior afinidade para o FvW (50).

\section{CONCLUSÃO}

Como observado, a hemofilia acomete um número elevado de pacientes, portanto faz-se necessário aperfeiçoar o acesso à informação tanto da população como da comunidade científica, visando diagnósticos precoces que possibilitem uma elevada expectativa de vida aos pacientes.

O diagnóstico desta doença baseia-se na história clínica do paciente e familiares com manifestações hemorrágicas apresentadas, principalmente sob a forma de hemartroses e hematomas, que variam de acordo com a gravidade da doença.

O diagnóstico laboratorial é fundamental para se determinar a deficiência do fator específico da coagulação, bem como, anular outras possíveis coagulopatias. Ensaios quantitativos para os fatores VIII e IX estabelecem o tipo e a gravidade da hemofilia. No coagulograma, os resultados do TP apresentam-se normais e o tempo de sangramento também, podendo sofrer prolongamento em aproximadamente $20 \%$ dos pacientes, principalmente os que apresentam deficiência grave. A principal prova de triagem é o TTPA que encontra-se alterado.

O tratamento é realizado pela reposição de fatores deficientes, no entanto, o desenvolvimento de inibidores pode tornar esse tratamento ineficaz. As alternativas para o tratamento desta doença é o uso da biotecnologia para surgimento de novos medicamentos e a terapia gênica que proporcionaria a produção endógena contínua dos fatores deficientes, protegendo o paciente de sangramentos espontâneos.

A profilaxia, como realização de exercícios físicos, também é um tratamento fundamental para o paciente hemofílico. Este não consiste na cura da doença, mas evita o aparecimento de sintomas como hemorragias, mas deve ser iniciado ainda na infância do paciente. 


\section{REFERÊNCIAS BIBLIOGRÁFICAS}

1. Almeida FA, Vidal TO. Hemofilia na infância: o impacto da doença sobre a atuação dos pais na educação da criança [Trabalho de conclusão de curso de Enfermagem]. São Paulo, Brasil: Hospital Israelita Albert Einstein. 2008.

2. Rodrigues N. Hemofilia: origem, transmissão e terapia génica Universidade Nova de Lisboa. 2005 [cited 2011 20/10]. Available from: http://biogilde.files.wordpress. com/2010/11/hemofilia. pdf.

3. BRASIL. Ministério da Saúde do Brasil. Manual de reabilitação na hemofilia. Elaborado por: Mônica Hermida Cerqueira et al. Brasília: 2011

4. Pio SF, et al. As bases moleculares da hemofilia A. Rev. da Assoc. Med. Bras. 2009; 55(2): 213-9.

5. Chaves DG, Rodrigues CV. Desenvolvimento de inibidores do fator VIII na hemofilia A. Rev. Bras. Hematol. Hemoter. 2009; 31(5): 384-90.

6. Manso VMC. Panorama histórico e distribuição da hemofilia no Brasil. 2011 [30 out. 2011]; Available from: http://www.inicepg. univap.br/ cd/INIC_2007/ trabalhos/saude/epg/EPG00098_01C. pdf.

7. Freire $\mathrm{M}$, et al. Hemofilia $\mathrm{A}$ adquirida associada à artrite reumatoide. Rev. Bras. Reumatol. 2009; 49(03): 302-9.

8. Bernard J, Lévy JP. Hematologia. 9 ed. Rio de Janeiro: Medsi, 1998. 336-339p.

9. Rapaport TS. Hematologia: introdução. São Paulo: Rocca. 1990. 403-9p.

10. Federação Brasileira de Hemofilia. A história da hemofilia. 2011 [10 jul. 2011]; Available from: http://www.hemofiliabrasil.org. br/historia_hemofilia.php.

11. Macedo, K. A fisiologia da coagulação sanguínea e as principais alterações que levam à hemofilia [Dissertação Curso Técnico em Laboratório em Biodiagnóstico em Sáude]. Brasília, Brasil: Escola politécnica Joaquim Venâncio, Fundação Osvaldo Cruz. 2005.

12. Associação Portuguesa de Hemofílicos. A história da hemofilia. 2011 [12 jul. 2011]; Available from: http://www.aphemofilicos.pt/

13. Carneiro J, Junqueira LCU. Histologia Básica. 10 ed. Rio de Janeiro: Guanabara Koogan. 2004. 237p.

14. Guyton AC, Hall JE. Tratado de Fisiologia Médica. 11 ed. Rio de Janeiro: Guanabara Koogan. 2006. 457p.

15. Silverthorn DU. Fisiologia Humana. 2 ed. São Paulo: Manole. 2003. 487-92p.

16. Carvalho WF. Técnicas Médicas de hematologia e imuno-hematologia. 8 ed. Belo Horizonte: Coopmed. 2008. 127-130p.

17. Massaro JD, et al. Dinâmica de Polimorfismos Genéticos Ligados ao Gene da Hemofilia A (F8) na População Brasileira. 2011 [13 jul. 2011]; Available from: http://rge.fmrp.usp.br > Início > Defesas > Tese.

18. Carvalho ES. Hemofilia A: Revisão Bibliográfica. Escola Bahiana de Medicina e Saúde Pública. Salvador- BA. 2007.

19. Rubin E, et al. Patologia: Bases Clinicopatológicas da Medicina. 4 ed. Rio de Janeiro: Guanabara Koogan. 2006. 272p.
20. Szajner P. Identificação e caracterização de alterações moleculares no gene do fator IX em pacientes com hemofilia B [Dissertação de Mestrado]. Campinas, Brasil: Universidade Estadual de Campinas. 1997.

21. Pierce BA. Genética: um enfoque conceitual. Rio de Janeiro: Guanabara Koogan. 2004. 12p.

22. Nussbaum RL, et al. Thompson \& Thompson Genética Médica. 6 ed. Rio de Janeiro: Elsevier. 2002. 59p.

23. Lorenzi TF. Manual de hematologia: propedêutica e clínica. 3 ed. Rio de Janeiro: Guanabara Koogan. 2003. 164-167 p.

24. Oldra M. Abordagem fisioterapêutica no tratamento e na prevenção das hemartroses em hemofílicos: revisão sistemática [Dissertação de Curso de Graduação em Fisioterapia]. Cascavel, Brasil: Universidade Estadual do Oeste do Paraná. 2003.

25. BRASIL. Ministério da Saúde do Brasil. Hemofilia congênita e inibidor: manual de diagnóstico e tratamento de eventos hemorrágicos. Elaborado por: Marcelo Thá Accioly Veiga, Suely Meireles Rezende, Silmara Aparecida Lima Montalvão. Brasília: 2009.

26. Say KG, et al. A fisioterapia na assistência a portadores de hemofilia. Rev. Biociênc. 2003; 9(1): 37-45.

27. Rodrigues MJ, et al. Prevalência de cárie e fatores associados em crianças hemofílicas. Rev. Bras. de Hematol. e Hemoter. 2008; 30(2): 114-19.

28. Pinto GM, et al. Hemofilia A. Porto Alegre: Fundação Faculdade Federal de Ciências Médicas de Porto Alegre. 2001. 30p.

29. Flores, R. P. G. et al. Hemofilia e Anestesia. Rev. Bras. Anestesiol. 2004; 54: 867-68

30. Marques RVCF, et al. Atendimento odontológico em pacientes com Hemofilia e Doença de Von Willebrand [Dissertação de Mestrado]. São Luís, Brasil: Universidade Federal do Maranhão - UFMA. 2010.

31. Gorziza RP. Caracterização das alterações genéticas em Hemofílicos A graves do Rio Grande do Sul [Dissertação de Mestrado]. Porto Alegre, Brasil: Universidade Federal do Rio Grande do Sul, 2012.

32. Garcia AA, Pintão MCT. Tratamento de Distúrbios Hemostáticos em Urgência Médica. Medicina. Ribeirão Preto, 36: 439-45, 2003.

33. Ravel R. Laboratório Clínico: aplicações clínicas dos dados laboratoriais. 6 ed. Rio de Janeiro: Guanabara Koogan. 1995. 83p.

34. Ferreira RR et al. Obtenção e caracterização de anticorpo monoclonal murinho anti-fator VIII da coagulação sanguínea. Rev. Bras. de Hematol. e Hemoter. 2006; 28(2): 97-104

35. Rezende SM, Pinheiro K, Caram C, Genovez G, Barca D. Registry of inherited coagulopathies in Brazil: first report. Haemophilia. 2009; 15: 142-149.

36. Oldenburg J, Pavlova A. Genetic risk factors for inhibitors to factors VIII and IX. Haemophilia. 2006; 12(6): 15-22.

37. BRASIL. Ministério da Saúde do Brasil. Manual de Atendimento Odontológico à Pacientes com Coagulopatias Hereditárias. Brasília: 2008 
38. Leite EST, Marques MPC. Cuidados nos pacientes com hemofilia e doença de von Willebrand na cirurgia eletiva otorrinolaringológica. Rev. Bras. Otorrinolaringol. 2003; 69(1): 40-46.

39. Vrabic ACA, Ribeiro CA, Ohara CVS, Borba RIH. Dificuldades para enfrentar sozinho as demandas do tratamento: vivências do adolescente hemofílico. Acta Paul Enferm. 2012; 25(2): 204-210.

40. Andery SCA, Galatti LR, Alves MLT, Duarte E. Exercício físico e hemofilia: conceitos e intervenção. Revista Mackenzie de Educação Física e Esporte. 2005; 11(2): 96-109.

41. Castilho-Fernandes A, Pessolato AGT, Fontes AM. Hemofilia B sob um olhar panorâmico. Rev.Univ.Vale do Rio Verde. 2012; 10(1): 275-89.

42. Ozelo MC. Terapia Gênica para hemofilia: novo estudo para hemofilia B grave. 2011 [08 jul. 2011]; Available from: http//www. hemofiliabrasil.org.br/ download.php?id=17

43. Menck CFM, Ventura AM. Manipulando genes em busca de cura: o futuro da terapia gênica. Revista USP. 2007; 75(1): 50-61.

44. Berntorp E, Shapiro AD. Modern haemophilia care. Lancet. 2012; 14(379): 1447-56.

45. Kempton CL, White GC. How we treat a hemophilia A patient with a factor VIII inhibitor. Blood. 2009; 113(1): 11-17.
46. Ozelo MC, Villaça PR, Almeida JOSC, Bueno TMF, Miranda PAP, Hart WM. A cost evaluation of treatment alternative for mild-to-moderate bleeding episodes in patients with haemophilia and inhibitors in Brazil. Haemophilia. 2007; 13(5): 462-9.

47. Carlsson KS, Astermark J, Donfield S, Berntorp E. Cost and outcome: comparison of two alternative bypassing agents for persons with haemophilia A complicated by an inhibitor. Thromb Haemost. 2008; 99: 1060-67.

48. Teitel JM, Sholzberg M. Current status and future prospects for the prophylactic management of hemophilia patients with inhibitor antibodies. Blood Rev. 2013; 27(2): 103-9.

49. Livnat T, Martinowitz U, Azar-Avivi S, Zivelin A, BrutmanBarazani T, Lubetsky A, Kenet G. Combined administration of FVIII and rFVIIa improves haemostasis in haemophilia A patients with high-responding inhibitors - a thrombin generationguided pilot study. Haemophilia. 2013; 10: 1-8.

50. Schulte, S. Innovative coagulation factors: albumin fusion technology and recombinant single-chain factor VIII. Tromb Res. 2013; 131(2): 52-6. 